\title{
A Systems View of Bio-inspiration: Bridging the Gaps
}

Norbert Hoeller (nhoeller@sinet.ca), Margo Farnsworth, Shoshanah Jacobs, Jacques Chirazi, Taryn Mead, Ashok Goel, and Filippo Salustri

\begin{abstract}
This paper provides an overview of biom*, an umbrella term for biomimicry, biomimetics, bio-inspired design, and related fields. The paper explores three levels of biom* bridging, discusses benefits and implications of adopting a systems perspective, and proposes initiatives for further development. Searching for 'sweet spots' leveraging the synergy between our aspirations, our growing knowledge of natural systems, and the market economy will improve the ability of biom* to deliver meaningful and impactful solutions.
\end{abstract}

\section{THE PROMISE}

Ellis and Ramankutty (2008) predict that we may soon be living in a world where less than $25 \%$ of our planet's ice-free land is unaffected by human activity. We are beginning to experience how crossing natural planetary boundaries for climate change, biochemical flows, land-system change, and biosphere integrity strains the resilience of our systems (Figure 1, Stockholm Resilience Centre 2015).

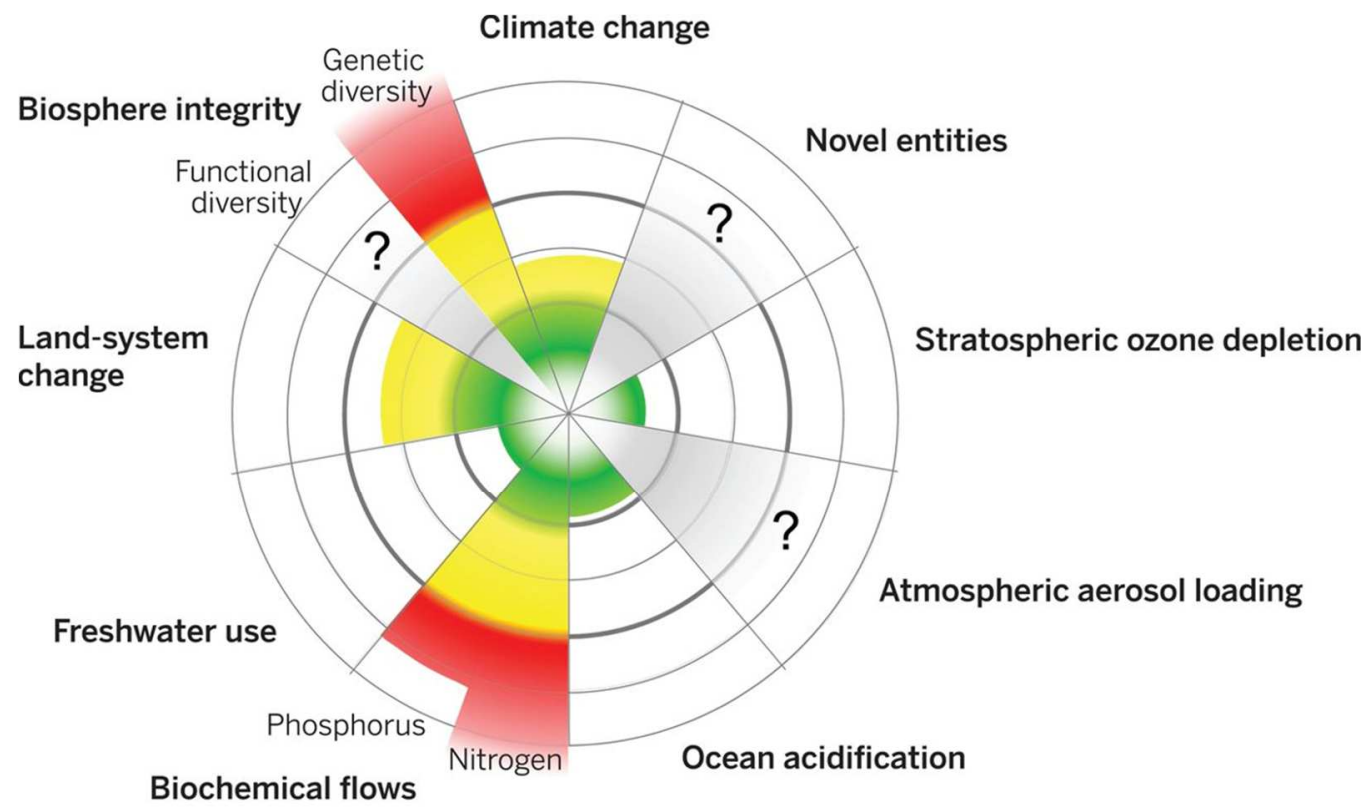

Beyond zone of uncertainty (high risk) In zone of uncertainty (increasing risk)
Below boundary (safe)

Boundary not yet quantified

Figure 1. Key Planetary Boundaries and their 2015 risk levels (credit: F. PharandDeschênes/Globä̈a)

"We cannot solve our problems with the same thinking we used when we created them." (Albert Einstein). Increasingly, we are looking to natural systems (NS), using methods such as biomimicry, biomimetics, and bio-inspired design (collectively referred to as biom $*$ in this 
paper) to develop more efficient, effective, and resilient solutions. "The biomimics are discovering what works in the natural world, and more important, what lasts.... The more our world looks and functions like this natural world, the more likely we are to be accepted on this home that is ours, but not ours alone." (Benyus 1997, 3)

Many NS have flourished for periods far exceeding the span of human history-while matching or exceeding the complexity of the challenges we face. NS exhibit a wide range of novel characteristics valued in engineered systems (Table 1), often sharing similar constraints and functional requirements with technological systems. NS appear to follow different solution pathways, opening up new avenues for disruptive innovation. Whereas we rely heavily on energy and materials (Figure 2), biological systems rely on information and hierarchy (Figure 3). Insect cuticle achieves a wide range of functional requirements by modifying proportions and orientation of chitin and matrix protein. In contrast, we typically develop an array of different compounds to satisfy unique requirements (Vincent et al. 2006, 475). Intentionally emulating nature's solutions and processes helps us leverage 'tried and tested' solutions that can be efficient, effective, resilient, ecologically appropriate, and less risky.

Table 1. The NS Challenge (Adapted from Studor 2014, 6)

\begin{tabular}{|c|c|c|}
\hline & Natural Systems & Human-Made Systems \\
\hline Size and Weight & $\begin{array}{l}\text { Efficient } \\
\text { Small } \\
\text { Tremendous growth }\end{array}$ & $\begin{array}{l}\text { Inefficient } \\
\text { Larger, heavier } \\
\text { No growth }\end{array}$ \\
\hline Materials & $\begin{array}{l}\text { Rigid and compliant } \\
\text { Self-healing } \\
\text { Multi-level assembly }\end{array}$ & Rigid, less compliant \\
\hline Mobility & $\begin{array}{l}\text { Many adaptable methods } \\
\text { Multiple environments }\end{array}$ & $\begin{array}{l}\text { Limited methods } \\
\text { Limited environments }\end{array}$ \\
\hline Feedback and Control & $\begin{array}{l}\text { Multiple sensor/control methods } \\
\text { Autonomic, instinctive } \\
\text { Learning }\end{array}$ & $\begin{array}{l}\text { Dedicated sensors, controllers } \\
\text { Limited/programmed capability } \\
\text { Rudimentary learning }\end{array}$ \\
\hline Computation & $\begin{array}{l}\text { Adaptive learning } \\
\text { Associative } \\
\text { Selective memory }\end{array}$ & $\begin{array}{l}\text { Limited computational speed } \\
\text { Limited processing methods }\end{array}$ \\
\hline Power Supply & $\begin{array}{l}\text { Auto-storage in multiple modes } \\
\text { Cycles of use/natural replenish }\end{array}$ & $\begin{array}{l}\text { Limited energy supplies } \\
\text { High power requirements } \\
\text { Safety/environmental issues }\end{array}$ \\
\hline Functionality & Highly multi-functional & Limited/designed in functionality \\
\hline Multi-systems & $\begin{array}{l}\text { Highly social } \\
\text { Learned interaction } \\
\text { Cooperation/competition }\end{array}$ & $\begin{array}{l}\text { Very limited cooperation } \\
\text { Limited cooperative functions } \\
\text { Rudimentary learning }\end{array}$ \\
\hline Reproduction & Automatic & Almost never \\
\hline
\end{tabular}




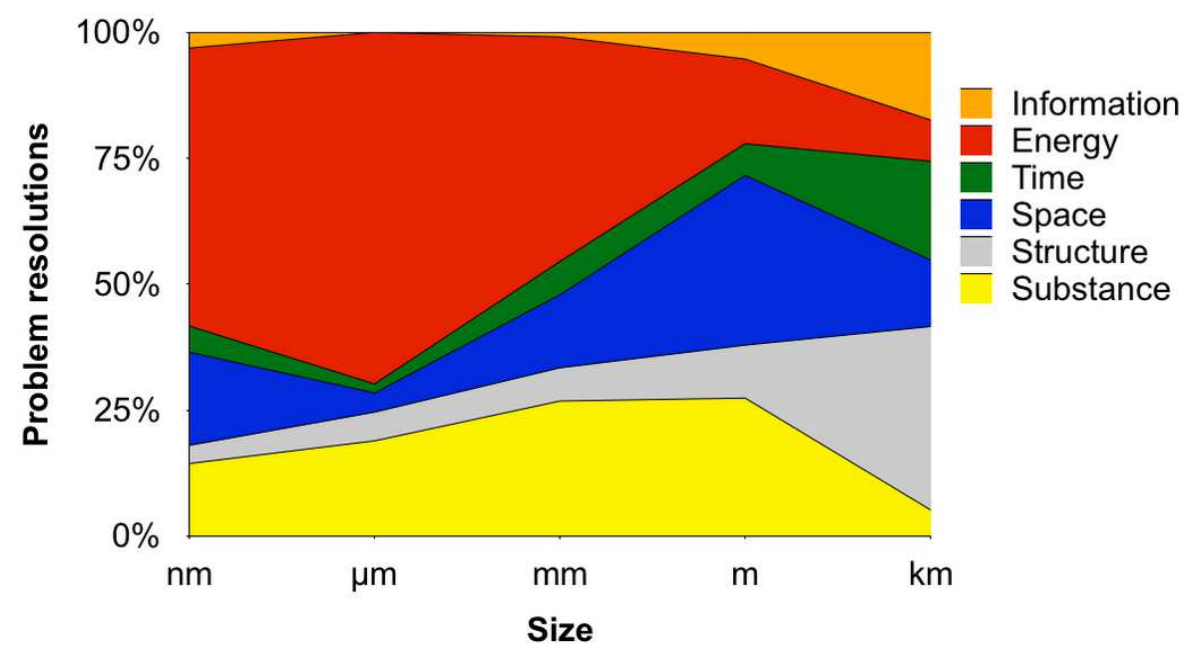

Figure 2. Engineering TRIZ solutions arranged according to size/hierarchy (Vincent et al. 2006) (TRIZ or "Theory of Inventive Problem Solving" is a Russian-developed tool derived from patterns found in patent literature.)

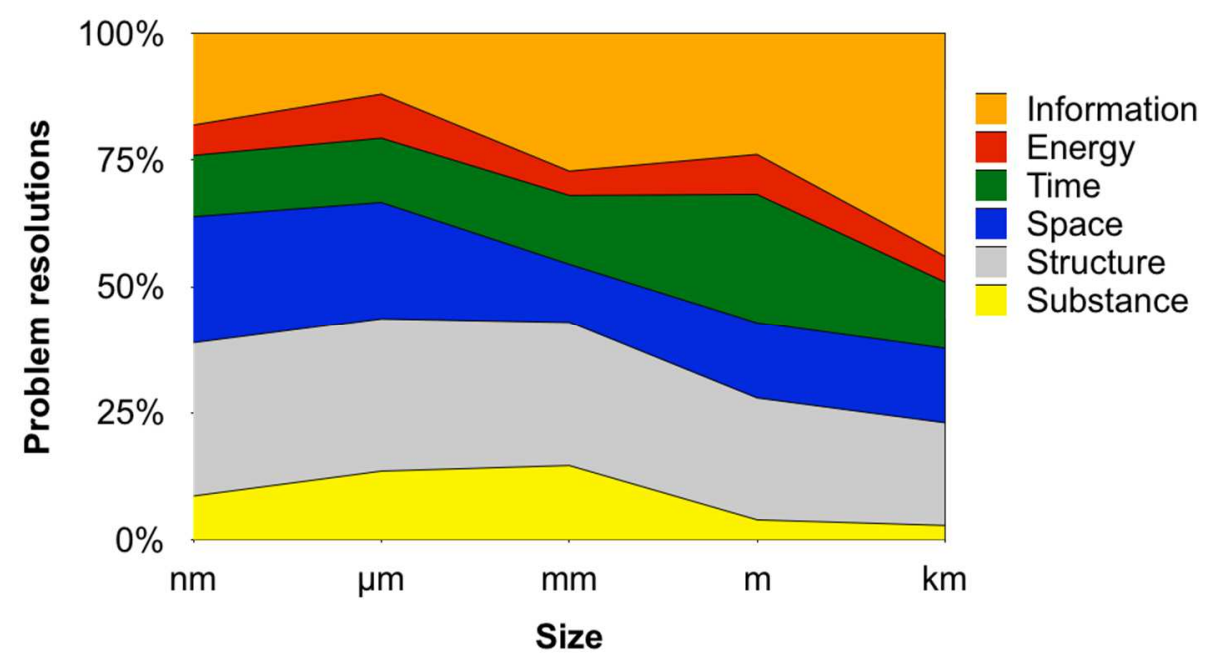

Figure 3. Biological effects arranged according to size/hierarchy (Vincent et al. 2006)

\section{A BIOM* BRIDGING MODEL}

Researchers and tool developers have done considerable work on the process of identifying the initial biom* model, often using analogies based on functional mapping. Researchers and developers have paid less attention to the complex steps required to transfer design elements that enable effective application of these initial analogies (Gentner 2003). The challenge is to incorporate knowledge from nature — not only at the 'eureka' moment, but also throughout the detailed design process.

Biomimicry 3.8 emphasizes the source of the inspiration by distinguishing emulation of forms, processes, and ecosystems (Baumeister et al. 2012, 54). This paper proposes a framework for design element transfer steps at the level of:

- Structure: the components of the system in question, their parameters, and their relationships

- Behavior: the internal causal processes of the system 
- Functional Role: the external outcomes of the system through interactions of the system with its external environment (the term "function" is used in the engineering sense of the role played by behavior in a larger context).

Bridging at the structural level involves similarities that are usually easily observed. It is harder to explore behavioral and functional relationships, but they can lead to richer analogies, providing deeper and more novel insights (Mak and Shu 2004).

Practicing biom* requires integrating a range of complexity levels, both in terms of the target situation and the source of biom* ideas. The three bridging levels correspond to the first three complexity levels of the Cynefin Framework (Snowden and Boone 2007) which can help the biom* practitioner identify whether a situation is simple, complicated, complex, or chaotic, and select appropriate responses (Figure 4). When dealing with complex systems, answers are rarely straightforward, leverage points are often counterintuitive, and apparently obvious interventions may have unintended consequences (Meadows 1999).

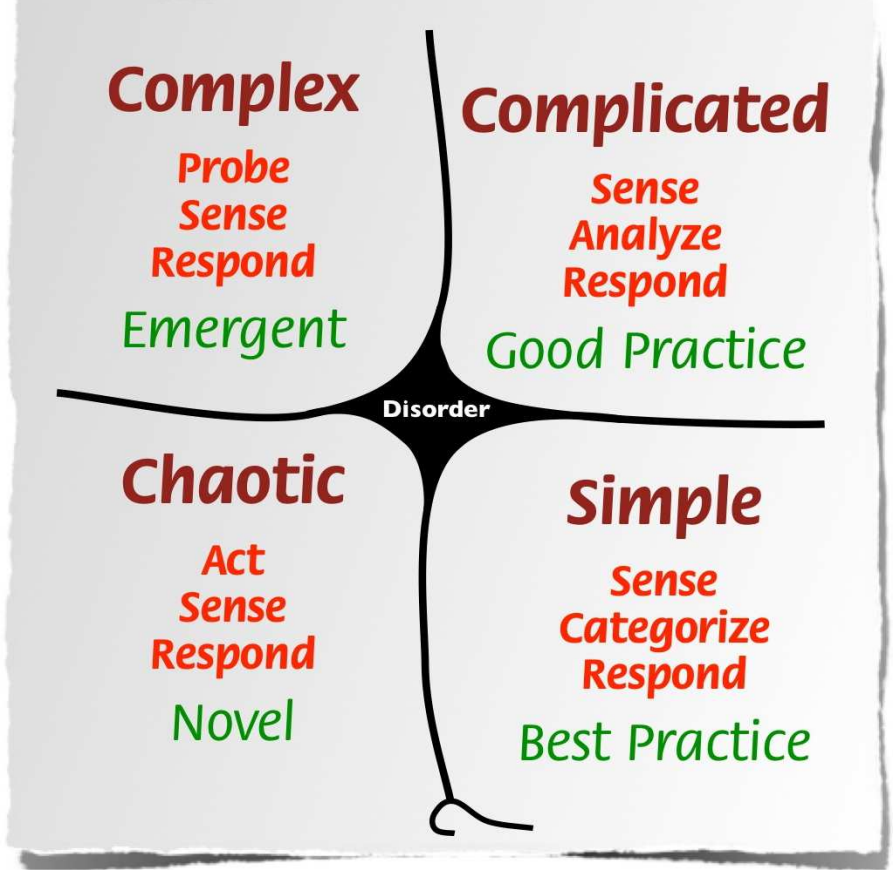

Figure 4. Five domains of the Cynefin framework (credit: Snowden/Wikimedia Commons)

Research into Structure-Behavior-Function (SBF) modeling supports this bridging model (Goel, Rugaber, and Vattam 2009). In SBF each structural component is itself a system, potentially with its own SBF model. DANE (Design by Analogy to Nature Engine) is an interactive tool for building and using digital libraries of biological and technological SBF models to help manage complexity (Goel et al. 2012).

\section{Structural Bridging}

In structural bridging, the desired effect directly relates to structural elements of the natural system. In Velcro®, the resemblance between burdock burrs and the "hook and loop" invention is evident. Another example is Lotusan ${ }^{\circledR}$ paint, which is based on the Lotus Effect (Barthlott and Neinhuis 1997). The desired effect of the surface cleaning itself when rinsed with water directly relates to surface microstructure, which mimics the surface structure of the lotus leaf. 
In both cases, the scale is consistent, and structural elements continued to function when isolated from their context. However, many larger aims of biom* have not been achieved.

Velcro® is typically manufactured using petroleum-based plastics (Reap, Baumeister, and Bras 2005). The microstructure of Lotusan ${ }^{\circledR}$ gradually deteriorates or can become contaminated by substances such as oils.

Our understanding of structures in nature and the relative ease of the structural bridging step may explain the preponderance of published cases. Most emphasize efficiency improvements, but impact is often limited. Although interdisciplinary collaboration is associated with biom*, anecdotal data suggests that it is not essential when structural bridging is involved.

\section{Behavioral Bridging}

In behavioral bridging, the design element undergoing transfer is a behavior or process that achieves a function within the system of interest. Structure is still important, but not sufficient. Given the right skills and analysis, principles underlying the behavior can be determined such that outcomes are predictable-even if the principles are implemented in a different shape or form.

The iconic shape of the original PAX Scientific (http://paxscientific.com/) 'lily impeller' (Figure 5) has been associated with the emulation of shape. However, higher efficiency, lower noise, and reduced turbulence derive from how the rotating impeller transforms the motion of fluids by managing turbulence, vortices, and dynamic instabilities (Fiske 2008). Recently PAX Scientific developed a fan blade that is more like a traditional fan (Figure 6).

Behavioral bridging can require extensive analysis to a) understand the principles underlying observed behaviors, b) determine that behaviors can be isolated safely from the biological context, and c) verify that any differences in scale will not impact performance. Our understanding of natural processes remains limited, but impacts can be far-reaching. An example is Green Chemistry (http://www.warnerbabcock.com/). Collaboration between specialists in both biology and the target innovation is often essential to success (Jacobs et al. 2014). In some cases, fundamental knowledge may not be available, thus exposing opportunities for specialists to create new knowledge that can be useful to both domains. 


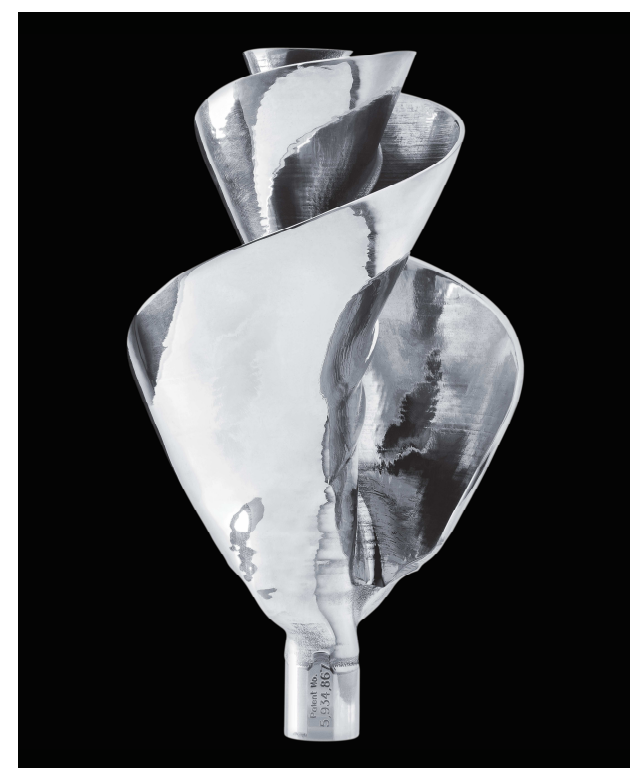

Figure 5. PAX 'lily' impeller (credit: PAX Scientific)

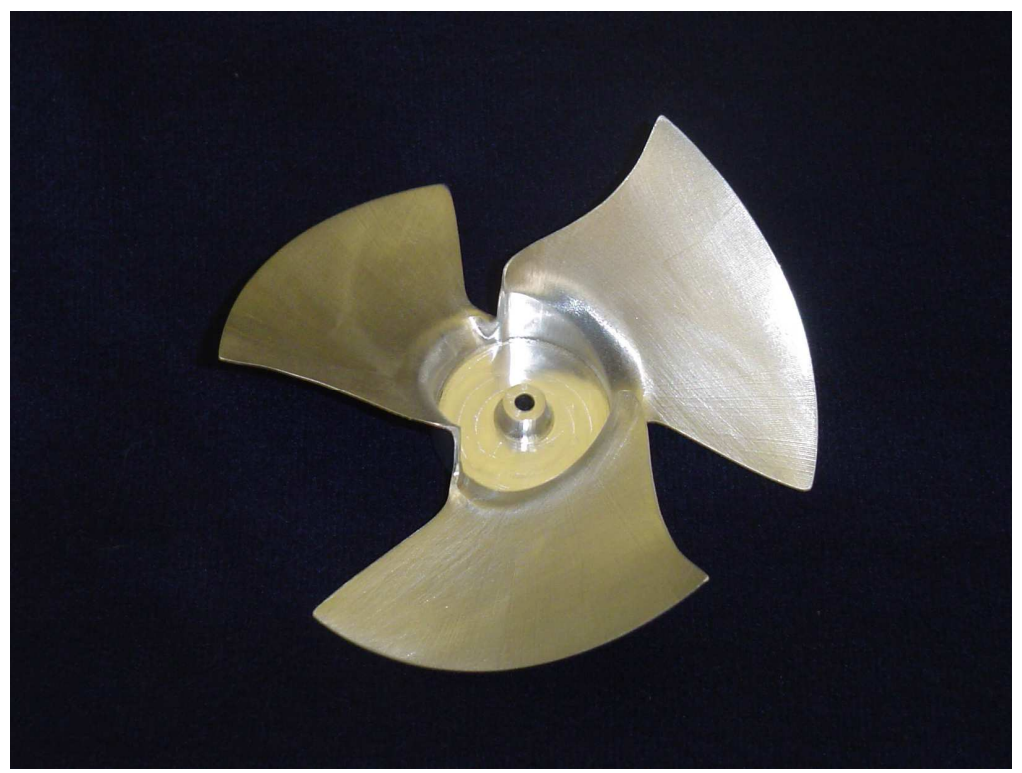

Figure 6. PAX biomimetic fan blade (credit: PAX Scientific)

\section{Functional Role Bridging}

As systems become more complex, desired effects often emerge at the super-system environment) level because of interactions between the system in question and peer systems. The degree of predictability can depend on scale, the same way statistical thermodynamics can predict aggregate behavior but not that of any particular molecule.

The Encycle (previously REGEN Energy) Swarm Logic controller (http://www.encycle.com/swarm-logic/) reduces peak electrical consumption by networking with other Encycle controllers using swarm theory principles. An individual Encycle Swarm Logic controller communicates with other controllers to decide when to switch on the attached electrical load, flattening peaks and valleys of electrical usage (Figure 7). The benefit occurs at the level of the controller network rather than individual controllers.

\section{Peak Demand Reduction}

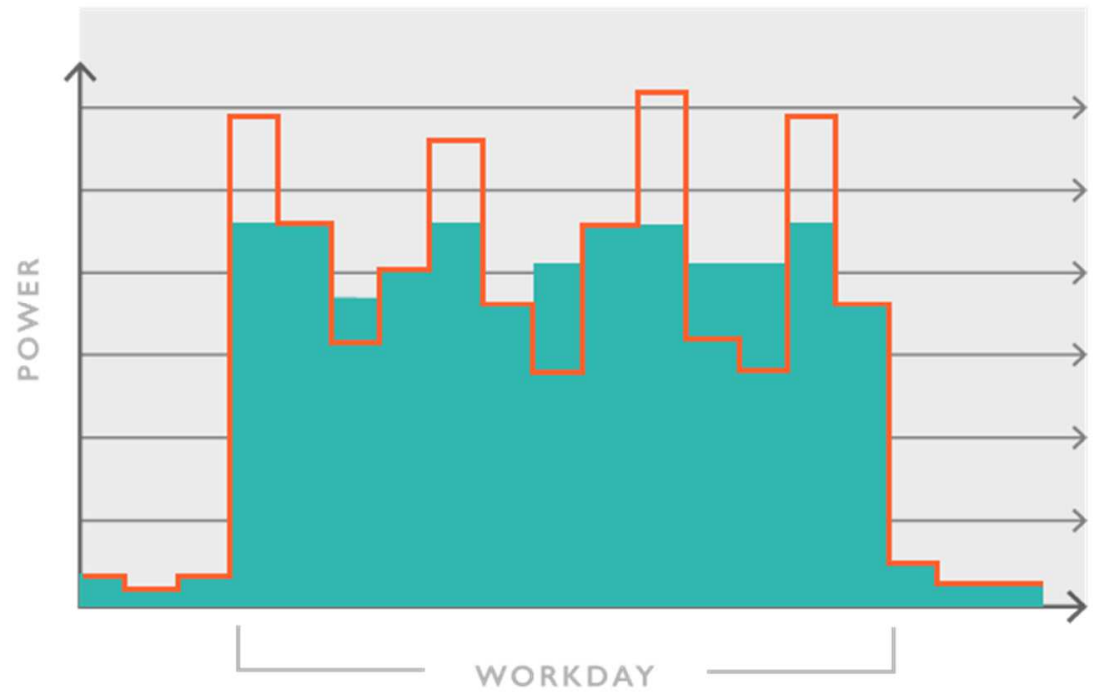

Figure 7 Load leveling (green area) by Encycle Swarm Logic controllers (credit: Encycle) 
Similarly, Dabiri's team applied principles learned from schooling fish (Whittlesey, Liska, and Dabiri 2010) to dramatically improve wind farm performance by leveraging the interaction between individual vertical axis wind turbines. John Dabiri (personal correspondence, 23 September 2015) confirmed that the aerodynamics of the farm are emergent, and different from those of the turbines themselves. Dabiri's innovation positions smaller turbines closer together (Figure 8), thus increasing energy density by an order of magnitude compared to traditional horizontal axis turbine farms. His findings could open the door to having rooftop wind farms on buildings in our cities.

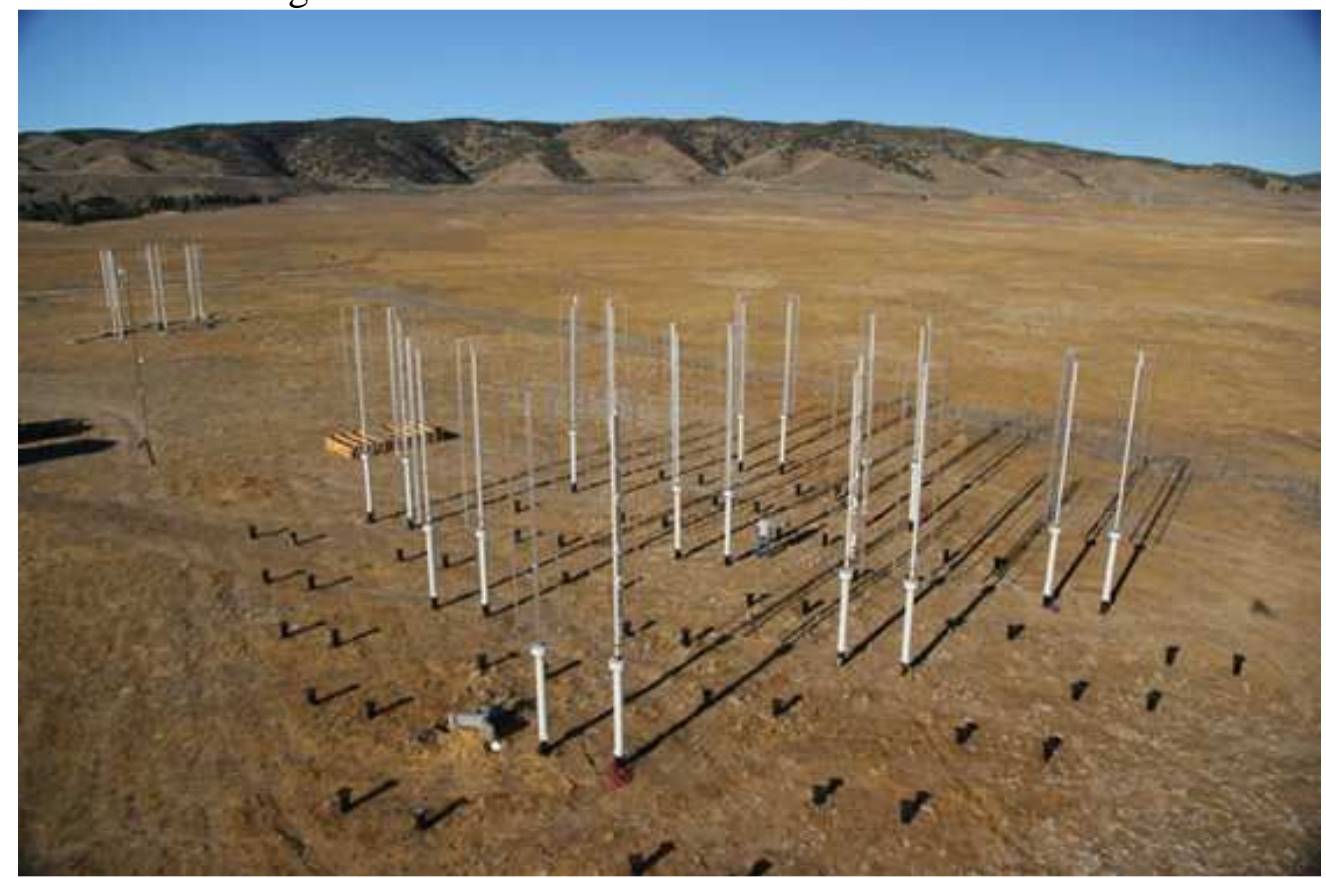

Figure 8 Caltech Field Laboratory for Optimized Wind Energy (credit: John Dabiri, Stanford)

Functional role bridging requires detailed analysis at multiple systems levels, with the goal of understanding underlying principles. If one validates these principles across a wide range of projects, scale and context mismatch become less of an issue than in other forms of bridging. Interventions at the system level can have wide impact by re-configuring interactions (rather than creating new components), allowing the system to attain greater effectiveness, health, and resiliency.

Functional role bridging is hampered by our limited knowledge of complex natural systems principles. Action research initiatives combining practice with research can help deliver results while simultaneously increasing understanding of complex systems. The "translational research model' (Woolf SH 2008) builds on action research by engaging key stakeholders early in project identification and development, enabling novel interventions while managing risk (Figure 9). Clinical research is increasingly adopting this model to facilitate effective collaboration between clinicians, biochemists, chemical compound suppliers, and the pharmaceutical industry.

The 'sweet spot' appears to be the intersection of unsatisfied needs, emerging capabilities, and gnarly situations (Figure 10) where 'business as usual' methods are not adequate. The INCOSE NSWG webinar series (https://sites.google.com/site/incosenswg/) illustrates the breadth of capabilities, including patterns (Rick Dove, February 2015), new approaches to 
adaptive robotics (Hod Lipson, June 2014) and process-inspired solutions (Russell Kerschmann, April 2015).

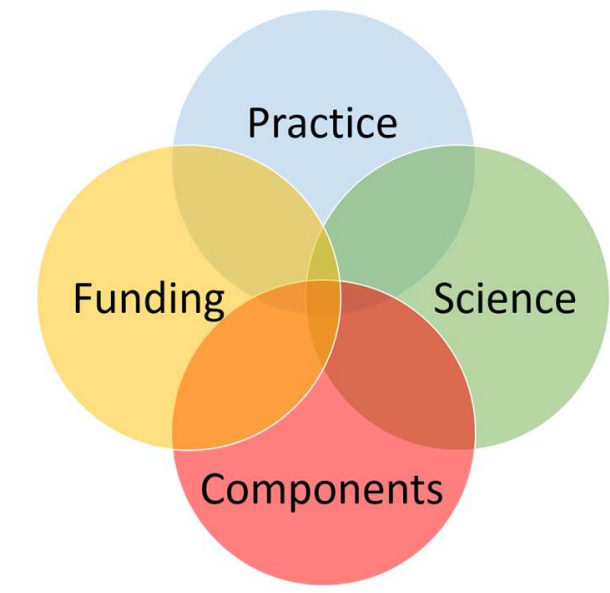

Figure 9 Translational Research Model

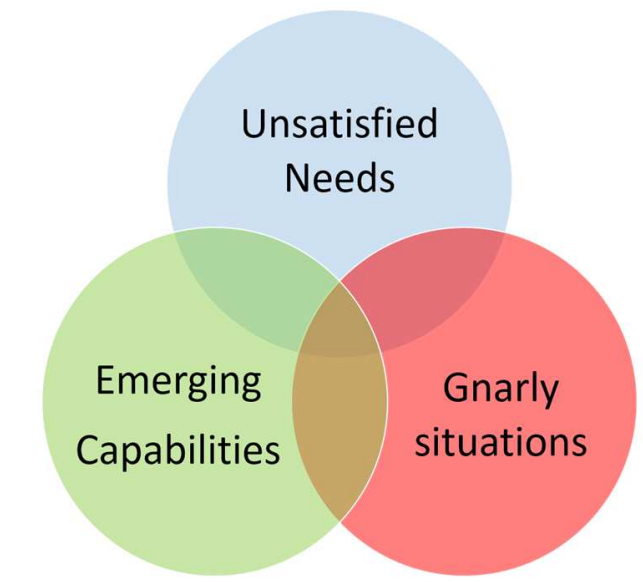

Figure 10 'Sweet spot' for systems biom*

\section{IMPLICATIONS FOR SYSTEMS ENGINEERING}

Biom* can help systems engineers solve problems where current methods are inadequate, access opportunities in fields not traditionally associated with engineering, and rekindle personal or professional interest in the natural world. Given the maturity of biom*, progress will require active collaboration between systems engineers and biom* practitioners through focused initiatives driven by small trans-disciplinary teams. We propose the following initiatives:

- Develop a common SE/biom* vocabulary and shared principles, building on an earlier biom* initiative (Hoeller et al. 2013).

- Deliver a systems-oriented biom* primer, covering key concepts, tools, methods and rules of thumb, with explanations and examples.

- Identify tangible challenges systems engineering cannot easily handle today.

- Identify high value biom* leverage points to deal with these challenges, specifying how, where and why biom* could provide value.

- Identify emerging biom* capabilities systems engineers could apply, including references, success stories, and support channels. Examples include swarm theory and biomimetic optimization opportunities (Gleich et al. 2010, 152-154).

- Build a library of credible, compelling case studies that demonstrate the value of biom* to business success.

- Develop investment strategies for biom*-focused systems engineering opportunities.

These initiatives will assist systems engineering in tapping underlying principles of NS to solve challenging problems. Although structural and behavioral bridging can lead to worthwhile innovation, functional role bridging can help systems engineers deal with situations that are more complex. Delivering effective systemic interventions can influence specific technologies, systems of technologies, and human behavior. In terms of broader impact, even small steps can 
increase resilience, the ability of systems to stabilize under stress and reconfigure themselves over time. Ultimately implementing all three types of bridging will be key to advancing biom* as a mainstream practice.

\section{REFERENCES}

- Barthlott, W., and C. Neinhuis. 1997. "Purity of the Sacred Lotus, or Escape from Contamination in Biological Surfaces." Planta 202 (1): 1-8.

- Baumeister, D., R, Tocke, J. Dwyer, S. Ritter, and J. Benyus. 2012. Biomimicry Resource Handbook. Missoula, US-MT: Biomimicry 3.8. http://biomimicry.net/educating/professional-training/resource-handbook/.

- Benyus, J. M. 1997. Biomimicry: Innovation Inspired by Nature. 1st ed. New York, USNY: William Morrow.

- Ellis, E. C., and N. Ramankutty. 2008. "Putting People in the Map: Anthropogenic Biomes of the World." Frontiers in Ecology and the Environment 6 (8): 439-47.

- Fiske, P. 2008. "Biomimetic Design of Fluid Handling." BioInspired! 6 (2): 2-3. http://bioinspired.sinet.ca/files/bioinspired/newsletters/bioinspired_v6.2b.pdf

- Gentner, D. 2003. "Analogical Reasoning, Psychology of.” In Encyclopedia of Cognitive Science, 1:106-12. London, UK: Nature Publishing Group.

- Gleich, A., C. Pade, U. Petschow, and E. Pissarskoi. 2010. Potentials and Trends in Biomimetics. 1st ed. Berlin Heidelberg, DE: Springer. http://www.springer.com/engineering/biomedical+engineering/book/978-3-642-05245-3.

- Goel, A. K., S. Rugaber, and S. Vattam. 2009. "Structure, Behavior, and Function of Complex Systems: The Structure, Behavior, and Function Modeling Language." AI EDAM 23 (Special Issue 01): 23-35. doi:10.1017/S0890060409000080.

- Goel, A. K., S. Vattam, B. Wiltgen, and M. Helms. 2012. "Cognitive, Collaborative, Conceptual and Creative - Four Characteristics of the next Generation of KnowledgeBased CAD Systems: A Study in Biologically Inspired Design.” Computer-Aided Design 44 (10): 879-900. doi:10.1016/j.cad.2011.03.010.

- Hoeller, N., A. Goel, C. Freixas, R. Anway, A. Upward, F. Salustri, and K. Miteva. 2013. "Developing a Common Ground for Learning from Nature." Zygote Quarterly 7: 133-45. https://www.academia.edu/13592692/Developing_a_Common_Ground for_Learning_from_Nature

- Jacobs, S.R., E.C. Nichol, and M.E. Helms. 2014. "Where Are We Now and Where Are We Going? The BioM Innovation Database.” Journal of Mechanical Design 136 (11): 111101.

- Mak, T. W., and L. H. Shu. 2004. "Abstraction of Biological Analogies for Design." CIRP Annals-Manufacturing Technology 53 (1): 117-20.

- Meadows, D. H. 1999. "Leverage Points: Places to Intervene in a System." Donella Meadows Institute. October 19. http://www.donellameadows.org/archives/leverage-pointsplaces-to-intervene-in-a-system/.

- Reap, J., D. Baumeister, and B. Bras. 2005. "Holism, Biomimicry and Sustainable Engineering." In Proceedings of IMECE2005. https://dspace.ist.utl.pt/bitstream/2295/390326/1/Support_10_Reap_2005.pdf.

- Snowden, D. J., and M. E. Boone. 2007. “A Leader's Framework for Decision Making." Harvard Business Review 85 (11): 68.

- Stockholm Resilience Centre. 2015. "Planetary Boundaries 2.0.” January 22. http://www.stockholmresilience.org/21/research/research-news/1-15-2015-planetary-boundaries2.0---new-and-improved.html. 
- Studor, G. 2014. "Natural Systems Working Group Introduction and Overview." January 14. https://sites.google.com/site/incosenswg/project-definition/iw-2014/nswg_overview.

- Vincent, J. F. V, O. A. Bogatyreva, N. R. Bogatyrev, A. Bowyer, and A. Pahl. 2006.

"Biomimetics: Its Practice and Theory." Journal of the Royal Society Interface 3 (9): 471-82.

- Whittlesey, R. W., S. Liska, and J. O. Dabiri. 2010. "Fish Schooling as a Basis for Vertical Axis Wind Turbine Farm Design.” Bioinspiration \& Biomimetics 5 (3): 035005. doi:10.1088/1748-3182/5/3/035005.

- Woolf, S. H. 2008. "The Meaning of Translational Research and Why It Matters." JAMA 299 (2): 211-13. doi:10.1001/jama.2007.26. https://www.chip.uconn.edu/chipweb/documents/DI/Woolf,\%202008.PDF.

\section{ABOUT THE AUTHORS}

After an extensive career in Information Technology at IBM, Norbert Hoeller founded the design research and consulting practice Sustainable Innovation Network. His primary areas of interest are tools and methods supporting systems-oriented, bio-inspired, sustainable design. Norbert has taught biomimicry and sustainability workshops at OCAD University, Brant Haldimand Norfolk Catholic District School Board, the Design Exchange, Ryerson University, the Nexus Student Sustainability Group (Auckland, New Zealand), Advanced Design and Manufacturing Institute (ADMI), and the University of Toronto. He is a director of BioDreamMachine (http://biodreammachine.org/), founder and practice leader of the Bio-Inspired Design Community (http://bioinspired.sinet.ca/), a co-editor of Zygote Quarterly (http://zajournal.org/), and chair of the Canadian mirror committee for ISO's Technical Committee \#266 on "Biomimetics" (http://www.iso.org/iso/iso_technical_committee?commid=652577).

Contributing authors:

- Margo Farnsworth, President, Screendoor Consulting and Biomimicry Institute Fellow (margo@screendoorconsulting.com)

- Shoshanah Jacobs, Assistant Professor, University of Guelph Department of Integrative Biology (sjacob04@uoguelph.ca)

- Jacques Chirazi, Clean Tech Program Manager, City of San Diego (jchirazi@gmail.com)

- Taryn Mead, ABIS Marie Curie Early Career Researcher, Business School, University of Exeter, UK (t.l.mead@exeter.ac.uk),

- Ashok Goel, Professor of Computer Science and Cognitive Science, Georgia Institute of Technology School of Interactive Computing (goel@cc.gatech.edu)

- Filippo Salustri, Associate Professor of Mechanical Engineering, Ryerson University (salustri@ryerson.ca). 